\title{
Course Property of Solfeggio in Normal College--Connotation Interpretation of three-Dimensional Steering
}

\author{
Xu Lu \\ College of Music ,Jiangxi University of Technology
}

Keywords: Solfeggio; Basic Music; Course Properties; Steering; Music Aesthetic; Culture Diversity; Human Spirit.

\begin{abstract}
The "Context", composed by the book Course Mentoring Program for students of College Music Education and Postmodernism Curriculum View, theoretically probes the course properties of College Solfeggio. The "Context" points out the course properties of this "basic music" has its historical limitations. Meanwhile, it emphatically discourses the dimensional steering of the course properties of College Music Education, so as to promote the course's sustainable development and also to echoes the basic music education. The teaching and research of Solfeggio have got widespread attentions and developed with a steady pace. Today, the Course accumulates amount of fruitful achievements for teaching and research, which promotes the overall development of music teachers' teaching level. Dose the College Solfeggio have its particularity? Are there only differences on music knowledge and technology, difficulty level and assessment level between College Solfeggio and the one in professional music institutions?
\end{abstract}

\section{Introduction}

Today in 21st Century, it is worthy for us to carefully figure out that where shall our College Music Education go under such domestic and foreign "context" siege as great changes happens for economical and cultural pattern of the world, a changeover is going for international music education idea and paradigm education courses sense of understanding and also the first step for domestic basic music education courses has been implemented. All is because of its great responsibility -the sacred duty to element basic music teachers.

"Solfeggio", as a technology of music training, firstly appeared in France. In early time, it was called "solfege" which originated from Italian word "solfeggio". Thereafter, it was named as sight-singing. At first, both of these two words mean the skill of sight-singing or sight-playing without rehearsal, and then they refer to the basic music education. Early in the 18th century, the two books Italy Solfege and Music Academy Solfege which were published in Paris became popular as sight-singing teaching method. Thereafter, musicians from the world gradually noticed that Solfeggio skill could help the music education with overall development,so as to list it as basic cours a basic course for music education. Along with its development and update, many unconventional contents has been added in to this basic course, such as simple music history, primary music analysis and basic knowledge of vocal and so on. Because of its extension and expansion, the name of it was changed from "solfege" into "formationmusicale" in late 1990s. Meanwhile, this change also reflects that the teaching idea of this course is in dynamic process of continuous development and gradual. 
Amount of musicians like Wedge, D'indy, Ravel, Hindemith, Dan Hauser, Raymond, Kodály and Ostrovsky wrote a lot of sightsinging etudes which were used by music schools of many countries in the hundreds years' developing history of "Solfeggio". Today, with countries like France, Germany, Italy, Great Britain and Russia as a representative, the Solfeggio course buiding has had hundreds years of history of educational tradition, and its teaching skill has been in the forefront level of the world. France, especially is worthy of the authoritative teaching of Solfeggio, which is not only because it has a long developing history and the music education sector in government pays great attentions on the course and the geographical advantages of this country (one of the Medieval religious music education center) but also importantly because generations of French music educators always put "Solfeggio" as the most important basic course and on the other hand put Solfeggio teaching and research as the equal important with other music skills. Although, Solfeggio started late in the United States, the speed of this course is fast and it has a prominent position in sight-singing field of modern music.

Comparing with music education in Western mainstream countries, the developing history of sight-singing course and teaching in China is not long. The whole course model is just following the way of Western music education and "ethnic additional mode" of Chinese musician sources. Moreover, there is just small difference of music education course design between normal schools and professional music universities. And the differences mainly reflect on music knowledge scope, degree of difficulty and the level of evaluation.

Starting from the first holding of music education in normal colleges, teaching and research of Solfeggio course was widely concerned and had a steady development. Until now, the course has accumulated a number of fruitful results of teaching and scientific research, which greatly contributes to the overall development of music teacher education. However, the course property of Solfeggio as a basic music skill in music education majors of normal colleges had been existed for a long time, and nearly continued without dispute until today. And it directly lead to a result that the instrumental value and practical purpose of sight-singing are intensified and its service role is strengthened. Meanwhile, under the direction of this course property, sight-singing teaching situation in normal colleges gradually falls into a dilemma.

Consequently, here become questions: Is there specialty exist in normal college sight-singing courses? Does it only have differences in music knowledge scope, degree of difficulty and the level of evaluation? This thesis has an agreement on the view that solfeggio course in normal colleges has its specialty comparing with the one in professional, so that it shall not be a simple reduction on course contents, criterion and number. It shall have a unique course property that carrying objective of cultivating music teacher education.

\section{Basic Music Section Change}

As all we know, the purpose of music major in normal colleges is to train talented persons who will become music teachers for the majority of primary and secondary schools in of basic music education field. And therefore, it requires the major shall be familiar with and understand the idea of the book Music Course Standard used in basic music teaching and shall pay close attentions on the new tendency of basic music education development and also shall regard the actual teaching needs as their training direction. For the basic music teaching major in normal colleges, they should effectively practice ideas of basic music education in the process of all courses. At the matter of fact, the curricula and the teaching model of music education in our country persistently had a disjointed 
problem with actual needs of it (although this phenomenon has been improved these years). The majors" "Discipline-center" tendency is strengthened and the contents based on skills operational level is over pursued and these two phenomenons caused out an obvious malpractice in normal college music education as the "technical education". And thereafter it makes the normal college music education go far from the course reality of the basic music education. In the book Music Course Standard (includes two standards for both compulsory and high school education), the music teaching idea of "music aesthetic core" is clearly pointed out. The idea undoubtedly will make an imperceptible influence on all majors of music education in normal colleges. Therefore, sense of music aesthetic must be permeated in each courses of music majors of normal colleges and meanwhile and motion of music aesthetic need to be enriched and developed, so as to keep close link and interconnected between normal college music education and the basic music education and to really play its role in guiding the practice of basic music education. In this way, after several years of music aesthetic "knowledge learning" through the learning of normal college courses, the idea then shall be put into class practice in basic music education. Consequently, those future music teachers will be very much familiar and at ease when they face the idea but not be helpless or confused. Meanwhile, among many professional course recourses of normal college music education, the Solfeggio has an outstanding superiority on performing music aesthetic in students' practice. And so, the thesis believes that the course properties of Solfeggio should be changed from "basic music subject" into "music aesthetic" considering the idea of Course Standard of basic music education.

In Music Course Standtard Explanations for full-time compulsory education, there is such a passage: It was not easy to keep the same pace with music aesthetic in music teaching because of influences from traditional system for subject education, such as read music training started from sheet music and notation, rhythm training based on training time and listening training focused on intervals and chords and so on. This kind of rational and boring machinery training could not make students produce music aesthetical experiences and could unavoidably make them dislike this kind of music study. The correct way was to make music teaching as a process of aesthetical awareness and detection. This passage that pointed the crux of missing of musical aesthetic in basic music education was a conclusion for music teaching problem happened before new course standards implemented. Also because of this kind of knowledge transfer view, music deviates from human living practice and emotional world. The Course Reform of basic music education confirms the educational idea of music aesthetic as the core, so as to "Enrich students' aesthetical emotion experiences to make them gain the ability of aesthetic, turn life abundant and colorful and make human elegant and full of love". So, the new Music Course Standard advocates making music teaching as a process of aesthetical awareness and detection to evoke students' aesthetic in music and enjoy music in aesthetic, and to make music experiences as the beautiful and indispensable element in the abundant emotional world. This undauntedly put forward a higher requirement for music teachers from basic music education, which is that they must have abundant music aesthetical emotion and deep music aesthetic experience. To sum it up, the music teachers shall have high music aesthetical attainments to suit the need of basic music education.

The education field of compulsory education Music Course Standard is divided into four parts: 1, feeling and appreciation, 2, performance, 3, creativity, 4, music and related culture, while the one for senior middle school has six model: 1, musical appreciation, 2, singing, 3, playing, 4, writing, 5, music and dance, 6, music and theatrical. From the angle of requirements of music aesthetic education, the first element of these two "Music Course Standard" is the same. The second element 
"performance" in compulsory education Music Course Standard corresponds with "singing" and "playing", while the "creativity" element contains the model of "writing" for senior middle school. Refer to fourth element of compulsory education, it more widely expands the two elements of "music and dance" and "music and theatrical" for senior middle school Music Course Standard, but the course connotations of this element will temporarily not be included in this paper, so it is not involved here. In view of the above, the paper will take the first three aspects of compulsory education Music Course Standard as examples to show the teaching idea with "music aesthetic" as the core. The purpose of it is to make music teachers notice about the music aesthetical attainment needed for practicing music aesthetical ideas of basic music education.

It can say that there are two motivated reasons for the aesthetical change of Solfeggio courses property in normal college. As discussed in last paragraph, the positive impact brought by music aesthetical idea of basic music education is its external emotion, while the internal emotion comes from existing malpractice of sight-singing course in normal college. Here are the malpractices: traditional sight-singing course has main content as training and resolving listening elements like pitch and rhythm, people focus on its instrumental and technical tool as a basic course under the influence of pragmatism concept, they pay attention on developing musical hearing in technical elements of each musical performance and laying a solid foundation for learning other music technique. Under the influence of this kind of course and teaching view, music turns into a nd stuffing with monotonous, boring and isolated "non-musical meaning". The course idea of changing into music aesthetic is just to comprehend it by puting each isolated sound and rhythm in the aesthetical "music context" and to fully enjoy the aesthetical pleasure brought from kinds of music information in audio listening and sight learning, not just to get knowledge of "acoustic sound" with strong physical attributes and lifeless.

Considering the music aesthetic, emotion cannot be ignored. Xie, Jiaxing mentions in his book Musical Context "emotion is the reason of music art, while musical emotion is a kind of aesthetical emotion"; "although knowledge on emotional conception is not the final aesthetical purpose but just the tool, emotional experiences cannot be ignored for music aesthetic"; "on the common psychoacoustic structure dimensions of human, music aesthetical emotion is indispensable". Undeniably, each musical basic performance feature plays important role in reflecting music aesthetical emotion process. People who learned about sight-singing know that the course involves almost all music performance elements. Just like what we see, it shall include basic elements of music like pitch, intensity, tone value and tone even for the hearing investigation of one isolate pitch, and which determines the universality and inclusiveness of musical aesthetic. However, it must be noticed that "a certain basic element cannot shall any specialty isolated, but possibly point into what direction in the whole process of musical appearance." By knowing this, we can avoid from losing overall music feeling caused by partial analysis.

The music education system of normal college is originated from the western countries. Consequently, in 20th century, the music courses and teaching is greatly influenced by Western instrumental rationality and modern scientific knowledge view. And also, they regard the mastery degree of western music technique and ability as the main knowledge acquisition target, and the training tool and method to achieving this target as the starting point. However, the sight-singing course's instrumental and practical purpose is over strengthened, and it is thought that the course's contents have properties of objective, scientific and universality. The author does not deny that training of music sense involves and needs technique which is never the music connotation. It must 
be paid great attention that music connotation would be lost if the technique is emphasized blindly and that would bring big negative influences to music teacher education majors.

If we put Solfeggio courses into the view of Musical Anthropology and under the background of international music education to consider and moreover combine it with the concept of multicultural music education proposed by normal colleges of our country, we would notice the significance of cultural diversity contained in Solfeggio courses. So then, the second dimension steering comes to be obvious.

Some foreign scholars once pointed: cultural patterns of change in today's world have three aspects. Firstly, under the influence of post-colonialism and the development of social, political and economic life, the people gradually have correct knowledge about the differences exist among each culture of the world and notice the parallel trend of international cultural integration and separation. Secondly, thanks to the development of technology and quicker speed of information transferring, distance from each people is suddenly shortened and different cultures impact to each other inevitably. In this way, all ethnic boundaries increasingly clear and the unique features of the various cultures is increasingly clear too. And on this basis, the people hopes to build a relationship of equality, respect and understanding but not a dialogue and exchanges under the hegemony in different countries, ethnics or cultures. Thirdly, the rapid growth of the number of migratory movements and worldwide and it makes the cultural diffusion even more significant. Meanwhile, one of the requirements of the changes of world's cultural pattern for music educational sense is to understand and implement multi-cultural or cross-cultural music education with a multicultural value.

It is exactly under the premise of agreement to the exists and value of all music in the world, the International Society for Music Education believes that the music's abundance and diversity provide equal opportunities to enhance international understanding, cooperation and mutual learning within every cultures.

The International Society for Music Education (ISME) was founded in 1953. As one of the subsidiary bodies of the UNESCO, ISME has increased its member states from 29 to 70 and had more than 2000 members. The Society holds the meeting once in every two years. By comprehensively observing it's nearly 50 years' development, four phases shall be divided:

1.Adjustment for relationship of eastern-western music (1953-1969); unequally critical awareness to eastern-western music

2.Awareness on independence and value of every music culture of the world (1970-1982)

3. Mutual effects of local and international within world's music (1983-1994)

4. "Statement of Faith" and "Music Policy of the World's culture" issued by ISME (1994-now)

ISME issued two political documents as "Statement of Faith" and "Music Policy of the World's culture" which shall the Society's proposal for music education worldwide. In "Music Policy of the World's culture", ISME stated 7 proposals in which the third and sixth ones were closely linked with normal college music education: understanding the minimum background of music of chosen culture shall be one part of all normal education courses; studying kinds of music materials which inherit from ancient and modern shall be included in music education in order to cultivate the sense and ability of musicians and listeners on aesthetical and political significance contained in all kinds of voice creating technology. Moreover, as a supplementary explanation of these recommendations, the document figures: "any of the music education system shall accept the fact of existing of the music world formed of multiple culture and the value of studying and understanding of it, and shall make 
this idea as the new starting point of normal music education"; "among all normal education courses, music model from worldwide culture shall be chosen to provide a minimum background knowledge for music understanding”. Proposals mentioned above clarifies that normal music education course shall have positive attitude on multicultural music of the world. While in the practice of normal music education, the course structure in many countries has been penetrated with education action of multicultural music.

Under the active promote and effort taken by UNESCO and ISME, the multicultural music educational idea has been put into practice in many countries of the world. In plus, the diversity value of music culture has got more and more affirmation and respects in music education world because of music anthropologists' broad participation. The world music culture which including the national one has got wide understanding and communication. At the same time, some of Chinese music scholars have sharply paid attention on this worldwide music education trend and have positively taken part into the academic research of multicultural music education. They firstly described and analyzed systematically on multicultural music education trend in other countries especially in western developed countries as America and also on the present situations of multicultural music education in developing countries, and thereby compared the thinking of music education, and discussed and introspected the short points of Chinese music education system, pointed out the lack of Chinese music education in maintaining world's cultural diversity, and too called for the implementation of the world multicultural music education as soon as possible.

Under the international background about multicultural music education, normal colleges in China have already gradually put it on the agenda. On the basis of an accurate grasp the idea of multicultural music education conferred by new Curriculum Mentoring Program of domestic normal colleges, they shall take an overlooking on music cultural diversity value of Solfeggio in normal colleges, and then permeate conception of multicultural music education into the educational practices. This undoubtedly will be back to reveal normal college Solfeggio course into diversity of music culture.

Professor Clay South, a musician from Germany once made an experiment course named "What makes a good music teacher". In terms of character of good music teachers, he convincingly mentioned the most important point of the five aspects which is to make relation with cultural differences. In the conclusion of the experiment course, he further informed: we would feel about the cultural differences more and more strongly by comparing different features of the outstanding teachers from different countries. Therefore, they must reinforce the foundation of their cultural identity, and making music courses facing foreign culture is one of the methods. This kind of music courses shall consider about the international musical communication and the local living status (formed by multiple culture) at the same. So, music teachers should have the ability to make contacts with multicultural experiences, manifestations and contents, etc. One of the important goals for normal college music education is to train the future outstanding music teachers who can be competent to the basic music education. The author believes that the ability of "making relation with cultural differences" mentioned by Clay South has the same inspiration on normal college music education in China. In the past, the normal colleges thought about course's building seldom from the angle of culture. And now, with the influence from international multicultural music education, they increasingly concern about the important role of cultural value played in world's music propagation and communication. Courses Mentoring Program is formed partially relying on international 
developing trend of normal music education. Therefore, the "program" as a directive book of music teacher education has thick color of "culture" too.

Diversity of music culture exists in everywhere, and the performance form of music is abundant as while. Both diversity and performance form of music records the developing history of human society and inherits the brilliant civilization of human. And all these can be richly experienced with novelty in Solffeggio curriculum sources of normal colleges. For example, "Solfeggio courses could take in rhythm and melody of different cultures, and of course the same for sight-singing and hear-writing. And if these training took place under the accompaniment of correct data recording, the students would get used to those cultural timbres and tuning systems and of which the method is very effective." Therefore in courses of Solfeggio, people shall understand the cultural context inheriting kinds of music style of human and shall teach students with stronger music hearing adaptability which means to gain "multiple sense of music" that can help students to appreciate all kinds of music and to promote them with trying for music creation.

\section{Conclusions}

Some experts of music say it is an indisputable fact that the teachers' curriculum consciousness is losing and their ability of curriculum development is low and which because people emphasize homogenization and standardization in the course process for a long time. This paper agreed with opinions stated above. To efficiently implement the Solfeggio in normal colleges, the teachers shall put curriculum sense and creative ability in an important place. Moreover, they shall change their understanding on curriculum which once was "learning division or subject", and shall consider curriculums as the main aspect of enjoying music and life for students but not the carriers of knowledge. Music teaching shall be a process of interaction and expanding of students' living and music cultural world. Only if they appreciate the comprehensiveness of music culture and living world, the students could be trained as comprehensive talented persons which shall be the important professional quality for the future music teachers. Turning back to life of course never means to ignore the academic knowledge and technical capacity of music which in contrast shall be taken as one of the indispensable parts for students to get growth in music and fulfill $t$ career of music teachers. Consequently, music teachers shall strengthen links between Solfeggio curriculum and students' life, spirit world and the music teaching of future basic education and to make them be integrated with each other efficiently. It does not mean to detach the Solfeggion from academic track, but to make it having more aesthetics, cultural diversity and more vigor and vitality of humanity by adding the theoretical source of modern time to the curriculum which has got through for hundreds years' development (starting from school education tradition of Solfeggio in France) and been technified.

After the publish of New Course Direction Program for music majors in normal colleges, related experts are writing teaching materials for each course. The paper has a willing that the views displayed above can give some inspiration for the writing teaching material of the course Music Theory and Sight Singing. It shall understand the course's context and arrange the course's contents by using curriculum view of postmodernism and shall fulfill the openness, diversity, inherent, creativity and ecological characters under the macroscopic direction of Course Direction Program. 


\section{References}

[1] Runyang Yu, Modern Western Music, Introduction to Philosophy, Hunan Educational Publisher, 2000

[2]Anguo Wang, Bing $\mathrm{Wu}$, Interpretation for Music Curriculum Standards, Beijing Normal University Publish, 2005

[3]Qian Zhang, Aesthetics of Music Guide, Shanghai Music Press, 2002

[4]Basic Education Sector of Education Ministry, Course Standards for Compulsory Education, 2001

[5]Litian Zeng, Music - Indulgence of Life, Publisher of Beijing University, 1994

[6]Hua Lin, Course for Music Aesthetic Psychology, Press of Shanghai Music College, 2005

[7]Jiaxing Xie, Context of Music, Press of Shanghai Music College, 2005

[8] Jiaxing Xie, Go into Music, Sichuan Renmin Publisher, 1999

[9] Bennett Ramo, Philosophy of Music Education, Renmin Music Publisher, 2003

[10]Hailin Xiu, Xiaoping Luo, General Theory of Music Aesthetics, Shanghai Music Press, 1999 